\title{
Mountain high and valley deep: epigenetic controls of pluripotency and cell fate
}

\author{
Tiziana A.L. Brevini ${ }^{1}$, Georgia Pennarossa, Elena F.M. Manzoni, Alessandro Zenobi, Fulvio Gandolfi
}

Laboratory of Biomedical Embryology, Centre for Stem Cell Research, Università degli Studi di Milano, Milan, Italy.

\begin{abstract}
All the somatic cells composing a mammalian organism are genetically identical and contain the same DNA sequence. Nevertheless, they are able to adopt a distinct commitment, differentiate in a tissue specific way and respond to developmental cues, acquiring a terminal phenotype. At the end of the differentiation process, each cell is highly specialized and committed to a distinct determined fate. This is possible thanks to tissue-specific gene expression, timely regulated by epigenetic modifications, that gradually limit cell potency to a more restricted phenotype-related expression pattern. Complex chemical modifications of DNA, RNA and associated proteins, that determine activation or silencing of certain genes are responsible for the 'epigenetic control' that triggers the restriction of cell pluripotency, with the acquisition of the phenotypic definition and the preservation of its stability during subsequent cell divisions. The process is however reversible and may be modified by biochemical and biological manipulation, leading to the reactivation of hypermethylated pluripotency genes and inducing cells to transit from a terminally committed state to a higher plasticity one.

These epigenetic regulatory mechanisms play a key role in embryonic development since they drive phenotype definition and tissue differentiation. At the same time, they are crucial for a better understanding of pluripotency regulation and restriction, stem cell biology and tissue repair process.
\end{abstract}

Keywords: cell plasticity, differentiation, epigenetics.

\section{Introduction}

The temporal order of gene expression plays a fundamental rule to ensure lineage commitment and cell fate determination Brevini et al., 2007. In 1942, Waddington coined the term 'epigenetics', which was defined as "changes in phenotype without changes in genotype". In recent years several studies have characterized the different mode of epigenetic regulation, such as DNA methylation, post-translational histone tail modifications, non-coding RNA control of chromatin structure, and nucleosome remodeling. All of them regulate the activation or repression of genes. Technological advances in epigenome analysis and pluripotent stem cell technologies have been driver for elucidating the epigenetic control of cellular identity during development and reprogramming.

Here, we provide a brief overview of the main epigenetic mechanisms, such as DNA methylation and histone modifications. We then review the available knowledge on the possibility to erase the epigenetic memory through the use of cell reprogramming technologies. We also give prospective views of the epigenetic direct conversion of one cell type into another, in a safe and robust way, for regenerative medicine.

\section{Cell commitment and Waddington model of epigenetic restriction}

Over 230 different cell types are present in an adult multicellular organism. Although they all derive from one single cell and are genetically identical (containing the same DNA sequence), they are able to differentiate in a tissue specific way and to respond to specific developmental cues. Indeed, at the end of the differentiation process, each cells is highly specialized and committed to a distinct determined fate. This is possible thanks to tissue-specific gene expression, timely regulated by epigenetic restrictions, that gradually limit cell potency (Hemberger et al., 2009) to a more limited phenotype-related expression pattern (Zhou and Melton, 2008).

More than 60 years ago, these concepts have been nicely depicted by Conrad Waddington, who first used the term "epigenetics" in his very famous landscape to describe the idea that a phenotype arises by a program, defined by the genome, under the influence of the organism's environment. In Waddington's metaphor, a ball represents the cell of an embryo, rolling from a non-committed, pluripotent condition down the hill, to a specific cell fate. The hill is marked by slopes and valleys representing the many different and complex process that characterize the events leading to cell differentiation. The ball is addressed along a progressively more restricted potency pathway, towards a favored position at the bottom of the hill, where the cell is unipotent and is characterized by a tissue specific differentiated state (Fig. 1).

Currently, epigenetics is at the center of modern biology, since it is considered a fundamental tool to understand stem cell biology as well as cell differentiation and de-differentiation processes. 


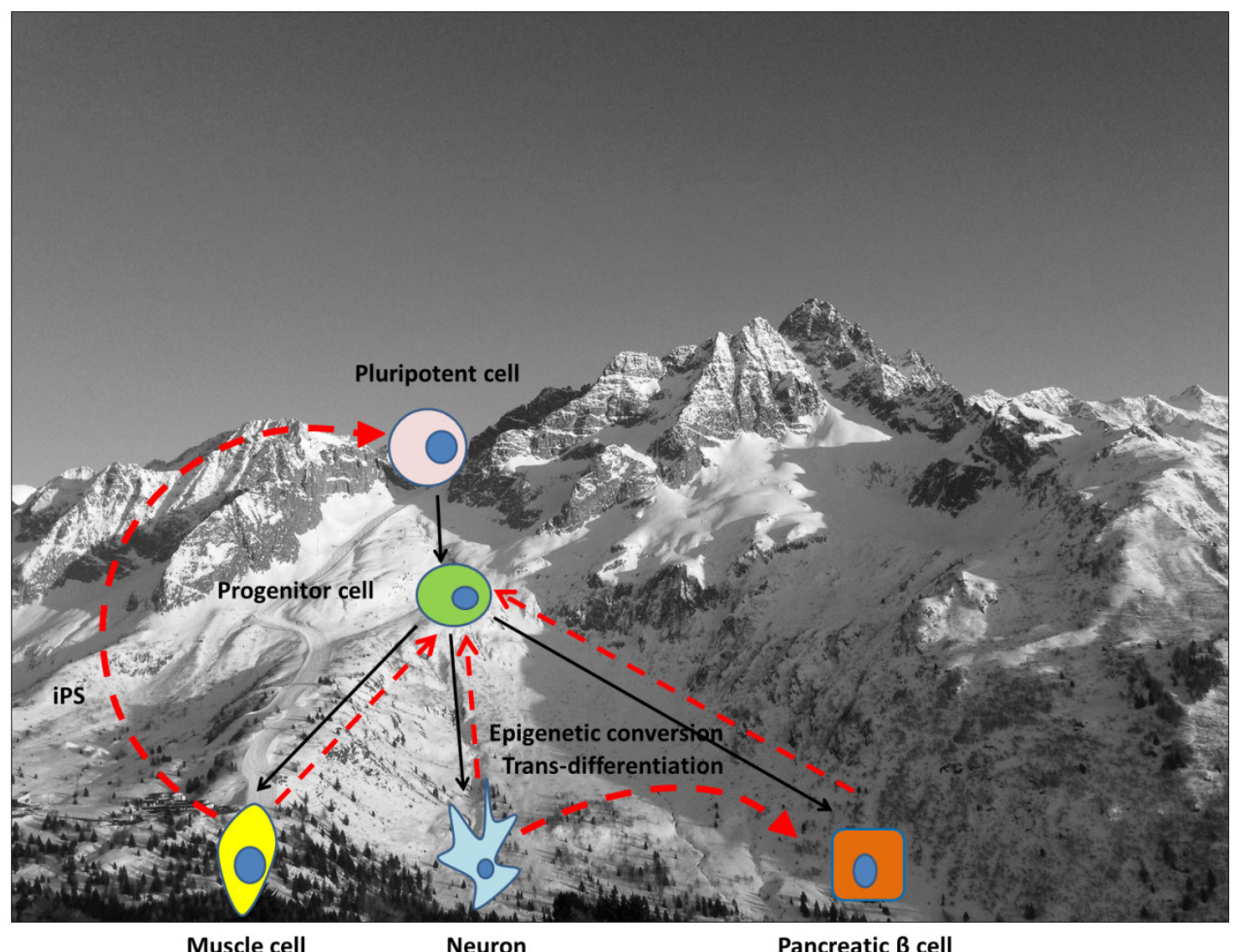

Figure 1. Representation of Waddington model. A pluripotent cell rolls from a non-committed condition down to the bottom of the hill, where the cell is unipotent and is characterized by a tissue specific differentiated state. The hill is marked by slopes and valleys, representing the many different and complex process that characterize the events leading to cell differentiation. Recent studies have shown that differentiated cells of an adult organism can be forced in an upstream, counter-current direction up the differentiation hill, transiting along different states of increased potency.

\section{Epigenetic control mechanisms and "epigenetic memory"}

The term "epigenetics" refers to complex chemical modifications of DNA, RNA and associated proteins, that determine activation or silencing of certain genes, without any permanent loss or alteration of genetic material (Goldberg et al., 2007; Xie et al., 2013). These mechanisms are responsible for the 'epigenetic memory' that triggers the phenotypic stability of the differentiated cell during subsequent cell divisions (Zhu et al., 2013; Jost, 2014; Shipony et al., 2014; Brevini et al., 2015).

There are several types of epigenetic modifications (Table 1) that play a fundamental role in the regulation of chromatin structure and gene expression, namely histone post-translational modifications, covalent modifications of DNA, small (21- to 26-nt) non-coding RNAs, and recombinations of non-genic DNA (Goldberg et al., 2007).
More in detail, histones can be subjected to acetylation, phosphorylation, methylation, SUMOylation, citrullination, ADP ribosylation, and ubiquitination (Spivakov and Fisher, 2007), that allow or prevent transcription factor and other protein access to DNA.

In parallel, the DNA can be methylated trough a covalent addition of a methyl $(\mathrm{CH} 3)$ group at the 5-carbon of the cytosine, that physically impedes the binding of transcription factor proteins to the gene (Choy et al., 2010) or recruits the methylCpG-binding domain proteins (MBDs). This modification also induces histone remodeling and the formation of compact, inactive chromatin, known as heterochromatin.

All these processes drive pluripotent cell differentiation and the acquisition of tissue specific epigenetic marks that are stable through the life span of a single individual and have been considered irreversible until not long ago. 
Brevini et al. Epigenetics, pluripotency and cell fate.

Table 1. Mechanisms involved in epigenetic control and related epigenetic enzymes.

\begin{tabular}{ll}
\hline \multicolumn{1}{c}{ Mechanism } & \multicolumn{1}{c}{ Epigenetic enzymes } \\
\hline DNA & DNA Methyltransferases \\
Methylation & DNA Demethylation Enzymes \\
& Methyl-CpG Binding Domains \\
Histone & Histone Acetyltransferases \\
Acetylation & Histone Deacetylases \\
& Bromodomains; Tandem PHD Fingers; Pleckstrin Homology Domains \\
& Protein Arginine Methyltransferases \\
Histone Arginine Methylation & Histone Demethylases \\
& Tudor Domains (recognize symmetrically dimethylated arginines); WD40 \\
& Domains \\
& Histone Lysine Methyltransferases \\
& Histone Lysine Demethylases \\
Histone Lysine Methylation & Chromodomains; Tudor Domains; PHD Fingers; MBT Domains; ZF-CW \\
& Proteins; WD40 Domains; PWWP \\
& Kinases (JAK2, ATM/ATR, PKC, PKA, Haspin, Aurora B Kinase, RSK2, \\
& AMPK, MSK, MEK) \\
& Protein Serine/Threonine Phosphatases; Protein Tyrosine Phosphatases \\
Histone Phosphorylation & Chromoshadow Domains (phosphoTyrosine); 14.3.3 Proteins \\
& (phosphoSerine); BIR Domains; BRCT Proteins \\
& Ubiquitin E2 Conjugases; Ubiquitin E3 Ligases \\
Histone Ubiquitination & Deubiquitinating Enzymes \\
\hline
\end{tabular}

\section{Erasing of "epigenetic memory"}

During the last years, many studies demonstrated that, although generally stable in vivo, the differentiated state of an adult cell can be reversed and forced in an upstream, counter-current direction up the Waddington's differentiation hill, along different states of increased potency (De Carvalho et al., 2010).

In 2006, the generation of induced pluripotent cells (iPSCs; Takahashi and Yamanaka, 2006) paved the way for a search of the mechanisms involved in the erasure of "epigenetic memory" and the re-establishment of pluripotency. Takahashi et al. demonstrated that an adult somatic cell can be brought back to an increased potency state, through the ectopic expression of four transcription factors (TFs; Takahashi and Yamanaka, 2006). Currently, various methodologies have been established for iPSC derivation, from virus-free (Okita et al., 2008, 2010; Kaji et al., 2009), to removable PiggyBac transposons (Woltjen et al., 2009), minicircle systems (Jia et al., 2010), episomal systems (Yu et al., 2009), synthetic mRNAs (Kim et al., 2009; Zhou et al., 2009; Warren et al., 2010), and microRNAs (AnokyeDanso et al., 2011; Miyoshi et al., 2011).

Nevertheless, cell reprogramming suffers from a number of severe limitations (Okita et al., 2007). In particular, its efficiency remains low (Mikkelsen et al., 2008; Pasque et al., 2012; Gaspar-Maia et al., 2013; Sridharan et al., 2013; Nashun et al., 2015), the extreme stability of adult somatic cell epigenetic signature makes iPSCs prone to errors (Plath and Lowry, 2011), and the use of DNA constructs and the subsequent possibility of exogenous sequence integration preclude their clinical use for safety concerns (Stadtfeld et al., 2008; Kim et al., 2009; Zhou and Freed, 2009; Seki et al., 2010). In order to circumvent these limits, small- molecule compounds have been used to modulate the epigenetic state by inhibiting and/or activating, in a reversible way, specific signaling pathways (Huangfu et al., 2008; Ichida et al., 2009; Li et al., 2011; Hou et al., 2013). A recent study revealed that the endogenous pluripotency program can be re-activated through the use of a combination of seven small-molecule compounds, namely valproic acid (VPA), CHIR99021, 616452, TCP, Forskolin (FSK), 2-methyl-5hydroxytryptamine (2-Me- 5HT), and D4476 (Hou et al., 2013). Similarly, it was also demonstrated that the use of VPA, in combination with an embryonic stem cell (ESC) medium, is able to revert somatic cells into pluripotent ones, in the absence of any transgenes (Moschidou et al., 2012; Rim et al., 2012).

These results represent a significant progress in cell reprogramming technology, demonstrating the possibility to use new approaches that avoid the presence of retroviral and/or lentiviral vectors, and the insertion of transgenes. However, the major concern related to the acquisition of a stable and persistent pluripotent state, remains unsolved. Indeed, the achievement of a stable pluripotency is an unphysiological condition, since, physiologically is transient and limited to a short time window, during the first phases of embryonic development. Furthermore, iPSCs display cell instability (Wu and Zhang, 2010), are difficult to differentiate with an efficiency that rarely exceeds $30 \%$, leaving mature cells mixed with undifferentiated and proliferating ones (Cohen and Melton, 2011).

Currently, all these aspects, severely limit the use of these cells in regenerative medicine, although useful information may be draw when using iPSCs, as a model for a detailed understanding of cell plasticity and differentiation 


\section{Epigenetic conversion: an alternative erasing of "epigenetic memory"}

During the last years new approaches allowing the direct conversion of an adult mature cell into another differentiated cell type have been developed. These methods are based on the use of small molecules and epigenetic modifiers (Table 2), and avoid the use of transgenes, stably integrated into the genome. In 2004 we can list the first paper reporting the ability of the small molecule reversine to increase cell plasticity, inducing lineage committed myoblasts to become multipotent mesenchymal progenitor cells (Chen et al., 2004). The activity of this molecule was subsequently tested in several type of cells, including 3T3E1 osteoblasts (Chen et al., 2007), human primary skeletal myoblasts (Chen et al., 2007), murine and human dermal fibroblasts (Anastasia et al., 2006), and confirming in all treated cells the induction of an increased plasticity.

Since that time, several protocols that involve the use of epigenetic modifiers have been developed They confirmed that specific chemical compounds can push cells to a transient less committed state, increasing cell plasticity for a relative short time-window, but sufficient to re-address an adult mature cell into another differentiated cell type (Harris et al., 2011; Pennarossa et al., 2013, 2014; Brevini et al., 2014; Mirakhori et al., 2015; Chandrakanthan et al., 2016).

A very general concept at the base of these experiments is that, among several mechanisms that drive cell differentiation, DNA methylation plays a fundamental role during both early embryonic development and cell lineage specification. To this purpose, de-methylating agents, which are wellcharacterized DNA methyltransferase (DNMT) inhibitor, were selected and used to erase DNA epigenetic restrictions. An example comes from 5azacytidine (5-aza-CR), that, when used at low doses, substitutes for cytosine and incorporate into DNA and RNA during replication (Stresemann and Lyko, 2008; Aimiuwu et al., 2012), forming covalent adducts with DNMT1. Thanks to its powerful effects, 5-aza-CR is able to induce global DNA hypo-methylation (Christman, 2002; Stresemann and Lyko, 2008), gene reactivation (Jones, 1985), and can facilitate adult somatic cell switch from one phenotype to a different one (Taylor and Jones, 1979; Glover et al., 1986; Harris et al., 2011).

In accordance with these findings, our laboratory demonstrated that an adult somatic cells can be converted into a new cell type after an $18 \mathrm{~h}$ exposure to 5-aza-CR (Pennarossa et al., 2013, 2014; Brevini et al., 2014, 2016). Cells acquired a 'highly permissive state' with significant changes in their phenotype and a specific gene regulatory response, that were paralleled by decrease in global DNA methylation. More in detail, following exposure to the demethylating agent, cells exhibited reduced dimensions with large nuclei, displayed a global chromatin decondensation and expressed pluripotency-related genes such as OCT4, NANOG, REX1 and SOX2. These are common features of ESC, iPSC and, more in general, of pluripotent cells (Tamada et al., 2006). It is interesting to consider that this condition was transient and reversible, and, if returned to their standard culture medium, cells reverted to their original phenotype. Expression of pluripotency related genes decreased gradually within a few days (Pennarossa et al., 2013, 2014; Brevini et al., 2014).

Once entered into the higher plasticity window, cells could easily be directed towards a different phenotype through the use of specific differentiation stimuli. In particular, adult skin fibroblasts, derived from different species namely human (Pennarossa et al., 2013; Brevini et al., 2014), porcine (Pennarossa et al., 2014), and dog (Brevini et al., 2016), were converted into pancreatic beta-cells through a three step pancreatic induction protocol. At the end of the epigenetic conversion, cells exhibited mature endocrine phenotype, expressing the main hormone and glucose sensor genes specific of the pancreatic tissue (Pennarossa et al., 2013, 2014; Brevini et al., 2016). The converted cell ability to restore normo-glycaemia and stably maintain glucose levels was also confirmed in vivo using diabetic mice (Pennarossa et al., 2013, 2014). Notably, we also demonstrated that epigenetic conversion can be applied to different cell types, such as granulosa cells that were converted into muscle cells through the use of 5-aza-CR followed by a 15 day culture with human recombinant vascular endothelial growth factor (VEGF; Brevini et al., 2014).

Furthermore, recent works carried out in other laboratories demonstrated the possibility to convert human skin fibroblasts into neural progenitor-like cells (Mirakhori et al., 2015) and mature bone and fat cells into tissue-regenerative multipotent stem (iMS) cells (Chandrakanthan et al., 2016) through the use of the demethylating agent 5-aza-CR, proving to be in agreement with our results. In addition, Cheng et al. reported that, using a cocktail containing inhibitors of histone deacetylation, glycogen synthase kinase and TGF- $\beta$ pathway, it is possible to convert human and murine fibroblasts into proliferating chemical-induced neural progenitor cells (ciNPC), under physiological hypoxic conditions (5\% O2; Cheng et al., 2015).

Furthermore, recent experiments described the possibility to epigenetically convert human skin fibroblasts into mature Schwann cells through the use of the histone deacetylase (HDAC) inhibitor VPA (Thoma et al., 2014). In that work, cells were stimulated with a two-step neural induction protocol, in order to obtain a transient population of proliferating neural precursors and, subsequently, terminally differentiated Schwann cells (iSCs), that showed neuro-supportive and myelination capacity, and expressed proteins specific of the peripheral nervous system. 
Table 2. List of epigenetic modifiers, their targets and applications.

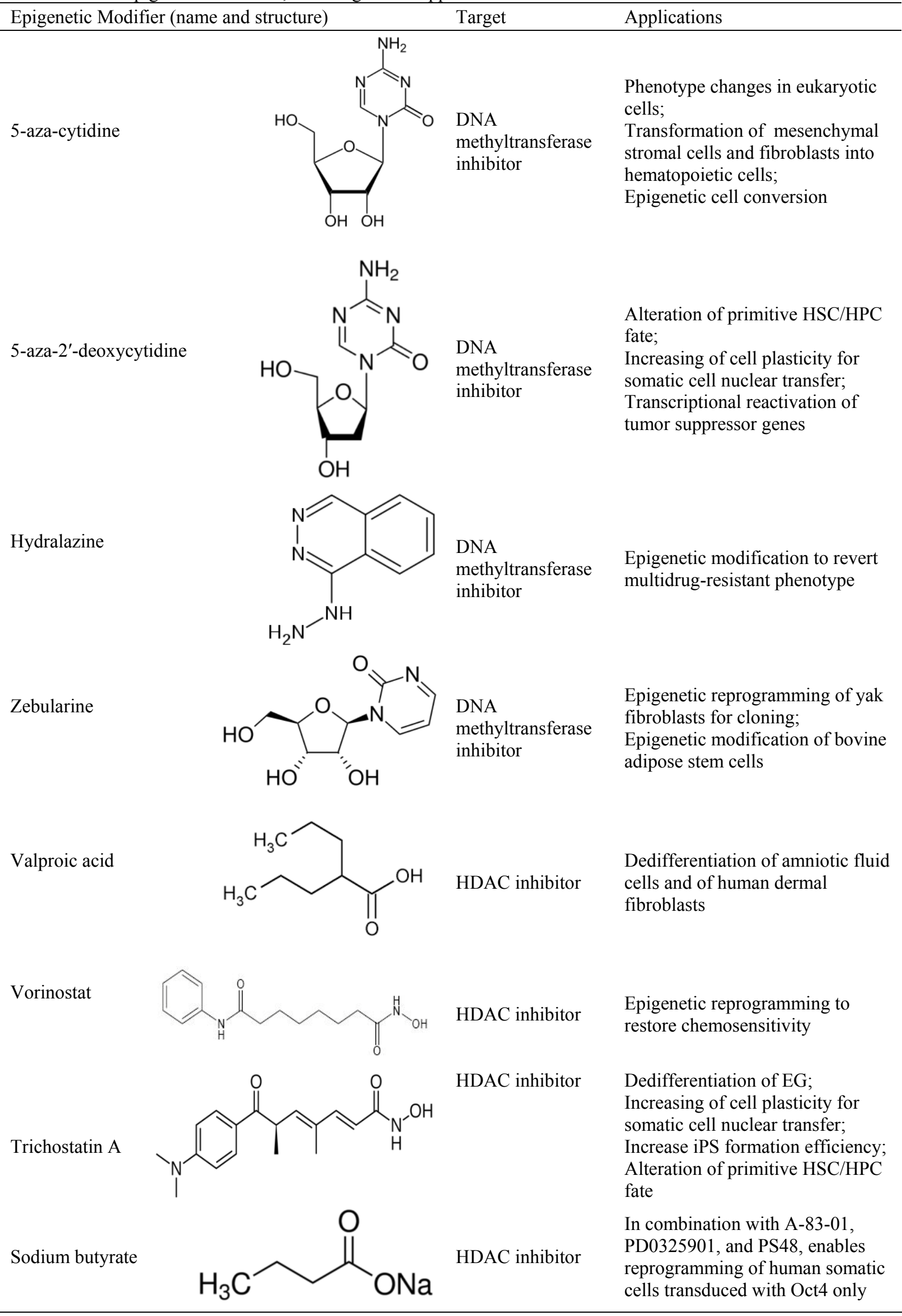




\section{Conclusions}

The growing understanding of the epigenetic regulatory mechanisms controlling cell differentiation provides new perspective for both the embryology and the cell biology field. Accumulating evidence point to epigenetic modifications, such as histone modification and DNA methylation, as key cellular events that exert a precise control over gene expression and allow a dynamic crosstalk between genotype and phenotype, leading to cell fate commitment and tissue specification. This has, in turn, further widened our understanding of the regulatory pathways involved in cell reprogramming, transdifferentiation and conversion, and has boosted the use of epigenetic modifiers and small molecules to revert cells to high plasticity states and encourage the acquisition of terminal phenotype.

Altogether the results accumulating have important implications for a better understanding of epigenetic cell fate control but is also advantageous for stem cell therapy and for regenerative medicine of human and animals.

\section{Acknowledgments}

The Author's work was funded by Carraresi Foundation and European Foundation for the Study of Diabetes (EFSD). GP is supported by a post-doc fellowship of the University of Milan. The Authors are members of the COST Actions FA1201 Epiconcept: Epigenetics and Periconception environment, BM1308 Sharing advances on large animal models (SALAAM), and CM1406 Epigenetic Chemical Biology (EPICHEMBIO).

\section{References}

Aimiuwu J, Wang H, Chen P, Xie Z, Wang J, Liu S, Klisovic R, Mims A, Blum W, Marcucci G, Chan KK. 2012. RNA-dependent inhibition of ribonucleotide reductase is a major pathway for 5-azacytidine activity in acute myeloid leukemia. Blood, 119:5229-5238.

Anastasia L, Sampaolesi M, Papini N, Oleari D, Lamorte G, Tringali C, Monti E, Galli D, Tettamanti G, Cossu G, Venerando B. 2006. Reversine-treated fibroblasts acquire myogenic competence in vitro and in regenerating skeletal muscle. Cell Death Differ, 13:2042-2051.

Anokye-Danso F, Trivedi CM, Juhr D, Gupta M, Cui Z, Tian Y, Zhang Y, Yang W, Gruber PJ, Epstein JA, Morrisey EE. 2011. Highly efficient miRNA-mediated reprogramming of mouse and human somatic cells to pluripotency. Cell Stem Cell, 8:376-388. Brevini TAL, Cillo, F, Antonini S, Tosetti V, Gandolfi F. 2007. Temporal and spatial control of gene expression in early embryo of farm animals. Reprod. Fertil Dev, 16: 35-42.

Brevini TA, Pennarossa G, Rahman MM, Paffoni A, Antonini S, Ragni G, deEguileor M, Tettamanti G, Gandolfi F. 2014. Morphological and molecular changes of human granulosa cells exposed to 5Azacytidine and addressed toward muscular differentiation. Stem Cell Rev, 10:633-642.

Brevini TA, Pennarossa G, Maffei S, Gandolfi F. 2015. Phenotype switching through epigenetic conversion. Reprod Fertil Dev, 27:776-783.

Brevini TA, Pennarossa G, Acocella F, Brizzola S, Zenobi A, Gandolfi F. 2016. Epigenetic conversion of adult dog skin fibroblasts into insulin-secreting cells. Vet J, 211:52-56.

Chandrakanthan V, Yeola A, Kwan JC, Oliver RA, Qiao Q, Kang YC, Zarzour P, Beck D, Boelen L, Unnikrishnan A, Villanueva JE, Nunez AC, Knezevic K, Palu C, Nasrallah R, Carnell M, Macmillan A, Whan R, Yu Y, Hardy P, Grey ST, Gladbach A, Delerue F, Ittner L, Mobbs R, Walkley CR, Purton LE, Ward RL, Wong JW, Hesson LB, Walsh W. Pimanda JE. 2016. PDGF-AB and 5Azacytidine induce conversion of somatic cells into tissue-regenerative multipotent stem cells. Proc Natl Acad Sci USA, 113:E2306-2315.

Cheng L, Hu W, Qiu B, Zhao J, Yu Y, Guan W, Wang M, Yang W, Pei G. 2015. Generation of neural progenitor cells by chemical cocktails and hypoxia. Cell Res, 25:645-646.

Chen S, Zhang Q, Wu X, Schultz PG, Ding S. 2004. Dedifferentiation of lineage-committed cells by a small molecule. J Am Chem Soc, 126:410-411.

Chen S, Takanashi S, Zhang Q, Xiong W, Zhu S, Peters EC, Ding S, Schultz PG. 2007. Reversine increases the plasticity of lineage-committed mammalian cells. Proc Natl Acad Sci USA, 104:1048210487.

Choy MK, Movassagh M, Goh HG, Bennett MR, Down TA, Foo RS. 2010. Genome-wide conserved consensus transcription factor binding motifs are hypermethylated. BMC Genomics, 11:519.

Christman JK. 2002. 5-Azacytidine and 5-aza2[prime]-deoxycytidine as inhibitors of DNA methylation: mechanistic studies and their implications for cancer therapy. Oncogene, 21:5483-5495.

Cohen DE, Melton D. 2011. Turning straw into gold: directing cell fate for regenerative medicine. Nat Rev Genet, 12:243-252.

De Carvalho DD, You JS, Jones PA. 2010. DNA methylation and cellular reprogramming. Trends Cell Biol, 20:609-617.

Gaspar-Maia A, Qadeer ZA, Hasson D, Ratnakumar K, Leu NA, Leroy G, Liu S, Costanzi C, ValleGarcia D, Schaniel C, Lemischka I, Garcia B, Pehrson JR, Bernstein E. 2013. MacroH2A histone variants act as a barrier upon reprogramming towards pluripotency. Nat Commun, 4:1565.

Glover TW, Coyle-Morris J, Pearce-Birge L, Berger C, Gemmill RM. 1986. DNA demethylation induced by 5-azacytidine does not affect fragile X expression. Am J Hum Genet, 38:309-318.

Goldberg AD, Allis CD, Bernstein E. 2007. Epigenetics: a landscape takes shape. Cell, 128:635638.

Harris DM, Hazan-Haley I, Coombes K, BuesoRamos C, Liu J, Liu Z, Li P, Ravoori M, Abruzzo L, Han L, Singh S, Sun M, Kundra V, Kurzrock R, Estrov Z. 2011. Transformation of human 
mesenchymal cells and skin fibroblasts into hematopoietic cells. PLoS One, 6:e21250.

Hemberger M, Dean W, Reik W. 2009. Epigenetic dynamics of stem cells and cell lineage commitment: digging Waddington's canal. Nat Rev Mol Cell Biol, 10:526-537.

Hou P, Li Y, Zhang X, Liu C, Guan J, Li H, Zhao T, Ye J, Yang W, Liu K, Ge J, Xu J, Zhang Q, Zhao Y, Deng H. 2013. Pluripotent stem cells induced from mouse somatic cells by small-molecule compounds. Science, 341:651-654.

Huangfu D, Maehr R, Guo W, Eijkelenboom A, Snitow M, Chen AE. 2008. Induction of pluripotent stem cells by defined factors is greatly improved by small-molecule compounds. Nat Biotechnol, 26:795797.

Ichida JK, Blanchard J, Lam K, Son EY, Chung JE, Egli D, Loh KM, Carter AC, Di Giorgio FP, Koszka K, Huangfu D, Akutsu H, Liu DR, Rubin LL, Eggan K. 2009. A small-molecule inhibitor of tgf-Beta signaling replaces sox 2 in reprogramming by inducing nanog. Cell Stem Cell, 5:491-503.

Jia F, Wilson KD, Sun N, Gupta DM, Huang M, Li Z, Panetta NJ, Chen ZY, Robbins RC, Kay MA, Longaker MT, Wu JC. 2010. A nonviral minicircle vector for deriving human iPS cells. Nat Methods, 7:197-199.

Jones PA. 1985. Effects of 5-azacytidine and its 2'deoxyderivative on cell differentiation and DNA methylation. Pharmacol Ther, 28:17-27.

Jost D. 2014. Bifurcation in epigenetics: implications in development, proliferation, and diseases. Phys Rev E Stat Nonlin Soft Matter Phys, 89:010701. doi: http://dx.doi.org/10.1103/PhysRevE.89.010701.

Kaji K, Norrby K, Paca A, Mileikovsky M, Mohseni P, Woltjen K. 2009. Virus-free induction of pluripotency and subsequent excision of reprogramming factors. Nature, 458:771-775.

Kim D, Kim CH, Moon JI, Chung YG, Chang MY, Han BS, Ko S, Yang E, Cha KY, Lanza R, Kim KS. 2009. Generation of human induced pluripotent stem cells by direct delivery of reprogramming proteins. Cell Stem Cell, 4:472-476.

Li Y, Zhang Q, Yin X, Yang W, Du Y, Hou P, Ge J, Liu C, Zhang W, Zhang X, Wu Y, Li H, Liu K, Wu C, Song Z, Zhao Y, Shi Y, Deng H. 2011. Generation of iPSCs from mouse fibroblasts with a single gene, Oct4, and small molecules. Cell Res, 21:196-204.

Mikkelsen TS, Hanna J, Zhang X, Ku M, Wernig M, Schorderet P, Bernstein BE, Jaenisch R, Lander ES, Meissner A. 2008. Dissecting direct reprogramming through integrative genomic analysis. Nature, 454:4955

Mirakhori F, Zeynali B, Kiani S, Baharvand $\mathbf{H}$. 2015. Brief azacytidine step allows the conversion of suspension human fibroblasts into neural progenitor-like cells. Cell J, 17:153-158.

Miyoshi N, Ishii H, Nagano H, Haraguchi N, Dewi Dyah L, Kano Y, Nishikawa S, Tanemura $M$, Mimori K, Tanaka F, Saito T, Nishimura J, Takemasa I, Mizushima T, Ikeda M, Yamamoto H, Sekimoto M, Doki Y, Mori M. 2011. Reprogramming of mouse and human cells to pluripotency using mature microRNAs. Cell Stem Cell, 8:633-638.

Moschidou D, Mukherjee S, Blundell MP, Drews K, Jones GN, Abdulrazzak H, Nowakowska B, Phoolchund A, Lay K, Ramasamy TS, Cananzi M, Nettersheim D, Sullivan M, Frost J, Moore G, Vermeesch JR, Fisk NM, Thrasher AJ, Atala A, Adjaye J, Schorle H, De Coppi P, Guillot PV. 2012. Valproic acid confers functional pluripotency to human amniotic fluid stem cells in a transgene-free approach. Mol Ther, 20:1953-1967.

Nashun B, Hill PW, Hajkova P. 2015. Reprogramming of cell fate: epigenetic memory and the erasure of memories past. EMBO J, 34:1296-1308.

Okita K, Ichisaka T, Yamanaka S. 2007. Generation of germline-competent induced pluripotent stem cells. Nature, 448:313-317.

Okita K, Nakagawa M, Hyenjong H, Ichisaka T, Yamanaka S. 2008. Generation of mouse induced pluripotent stem cells without viral vectors. Science, 322:949-953.

Okita K, Hong H, Takahashi K, Yamanaka S. 2010. Generation of mouse-induced pluripotent stem cells with plasmid vectors. Nat Protoc, 5:418-428.

Pasque V, Radzisheuskaya A, Gillich A, Halley-Stott RP, Panamarova M, Zernicka-Goetz M, Surani MA, Silva JC. 2012. Histone variant macroH2A marks embryonic differentiation in vivo and acts as an epigenetic barrier to induced pluripotency. J Cell Sci, 125:6094-6104.

Pennarossa G, Maffei S, Campagnol M, Tarantini L, Gandolfi F, Brevini TA. 2013. Brief demethylation step allows the conversion of adult human skin fibroblasts into insulin-secreting cells. Proc Natl Acad Sci USA, 110:8948-8953.

Pennarossa G, Maffei S, Campagnol M, Rahman MM, Brevini TA, Gandolfi F. 2014. Reprogramming of pig dermal fibroblast into insulin secreting cells by a brief exposure to 5-aza-cytidine. Stem Cell Rev, 10:3143.

Plath K, Lowry WE. 2011. Progress in understanding reprogramming to the induced pluripotent state. Nat Rev Genet, 12:253-265.

Rim JS, Strickler KL, Barnes CW, Harkins LL, Staszkiewicz J, Gimble JM, Leno GH, Eilertsen KJ. 2012. Temporal epigenetic modifications differentially regulate ES cell-like colony formation and maturation. Stem Cell Discov, 2:45-57.

Seki T, Yuasa S, Oda M, Egashira T, Yae K, Kusumoto D, Nakata H, Tohyama S, Hashimoto H, Kodaira M, Okada Y, Seimiya H, Fusaki N, Hasegawa M, Fukuda K. 2010. Generation of induced pluripotent stem cells from human terminally differentiated circulating T cells. Cell Stem Cell, 7:1114.

Shipony Z, Mukamel Z, Cohen NM, Landan G, Chomsky E, Zeliger SR, Fried YC, Ainbinder E, Friedman N, Tanay A. 2014. Dynamic and static maintenance of epigenetic memory in pluripotent and somatic cells. Nature, 513:115-119.

Spivakov M, Fisher AG. 2007. Epigenetic signatures of stem-cell identity. Nat Rev Genet, 8:263-271. 
Sridharan A, Chen Q, Tang KF, Ooi EE, Hibberd ML, Chen J. 2013. Inhibition of megakaryocyte development in the bone marrow underlies dengue virus-induced thrombocytopenia in humanized mice. $J$ Virol, 87:11648-11658.

Stadtfeld M, Nagaya M, Utikal J, Weir G, Hochedlinger K. 2008. Induced pluripotent stem cells generated without viral integration. Science, 322:945949.

Stresemann C, Lyko F. 2008. Modes of action of the DNA methyltransferase inhibitors azacytidine and decitabine. Int $J$ Cancer, 123:8-13.

Takahashi K, Yamanaka S. 2006. Induction of pluripotent stem cells from mouse embryonic and adult fibroblast cultures by defined factors. Cell, 126:663-676.

Tamada H, Van Thuan N, Reed P, Nelson D, Katoku-Kikyo N, Wudel J, Wakayama T, Kikyo N. 2006. Chromatin decondensation and nuclear reprogramming by nucleoplasmin. Mol Cell Biol, 26:1259-1271.

Taylor SM, Jones PA. 1979. Multiple new phenotypes induced in 10T1/2 and 3T3 cells treated with 5azacytidine. Cell, 17:771-779.

Thoma EC, Merkl C, Heckel T, Haab R, Knoflach F, Nowaczyk C, Flint N, Jagasia R, Jensen Zoffmann S, Truong HH, Petitjean P, Jessberger S, Graf $M$, Iacone R. 2014. Chemical conversion of human fibroblasts into functional Schwann cells. Stem Cell Reports, 3:539-547.

Warren L, Manos PD, Ahfeldt T, Loh YH, Li H, Lau F, Ebina W, Mandal PK, Smith ZD, Meissner A, Daley GQ, Brack AS, Collins JJ, Cowan C, Schlaeger TM, Rossi DJ. 2010. Highly efficient reprogramming to pluripotency and directed differentiation of human cells with synthetic modified
mRNA. Cell Stem Cell, 7:618-630.

Woltjen K, Michael IP, Mohseni P, Desai R, Mileikovsky M, Hamalainen R. 2009. piggyBac transposition reprograms fibroblasts to induced pluripotent stem cells. Nature, 458:766-770.

Wu SC, Zhang Y. 2010. Active DNA demethylation: many roads lead to Rome. Nat Rev Mol Cell Biol, 11:607-620.

Xie R, Everett LJ, Lim HW, Patel NA, Schug J, Kroon E, Kelly OG, Wang A, D'Amour KA, Robins AJ, Won KJ, Kaestner KH, Sander M. 2013. Dynamic chromatin remodeling mediated by polycomb proteins orchestrates pancreatic differentiation of human embryonic stem cells. Cell Stem Cell, 12:224-237.

Yu J, Hu K, Smuga-Otto K, Tian S, Stewart R and Slukvin, II. 2009. Human induced pluripotent stem cells free of vector and transgene sequences. Science, 324:797-801

Zhou H, Wu S, Joo JY, Zhu S, Han DW, Lin T. 2009. Generation of induced pluripotent stem cells using recombinant proteins. Cell Stem Cell, 4:381-384.

Zhou Q, Melton DA. 2008. Extreme makeover: converting one cell into another. Cell Stem Cell, 3:382388 .

Zhou W, Freed CR. 2009. Adenoviral gene delivery can reprogram human fibroblasts to induced pluripotent stem cells. Stem Cells, 27:2667-2674.

Zhu J, Adli M, Zou JY, Verstappen G, Coyne M, Zhang X, Durham T, Miri M, Deshpande V, De Jager PL, Bennett DA, Houmard JA, Muoio DM, Onder TT, Camahort R, Cowan CA, Meissner A, Epstein CB, Shoresh N, Bernstein BE. 2013. Genome-wide chromatin state transitions associated with developmental and environmental cues. Cell, 152:642-654. 